\title{
Successful Vascular Intervention Without Embolic Complications in Budd-Chiari Syndrome
}

Eiji Taguchi, MD; Junjiroh Koyama, MD; Masataka Kajiwara, MD;

Masayuki Inoue, MD; Yoko Horibata, MD; Kazuhiro Nishigami, MD;

Koichi Nakao, MD; Tomohiro Sakamoto, MD
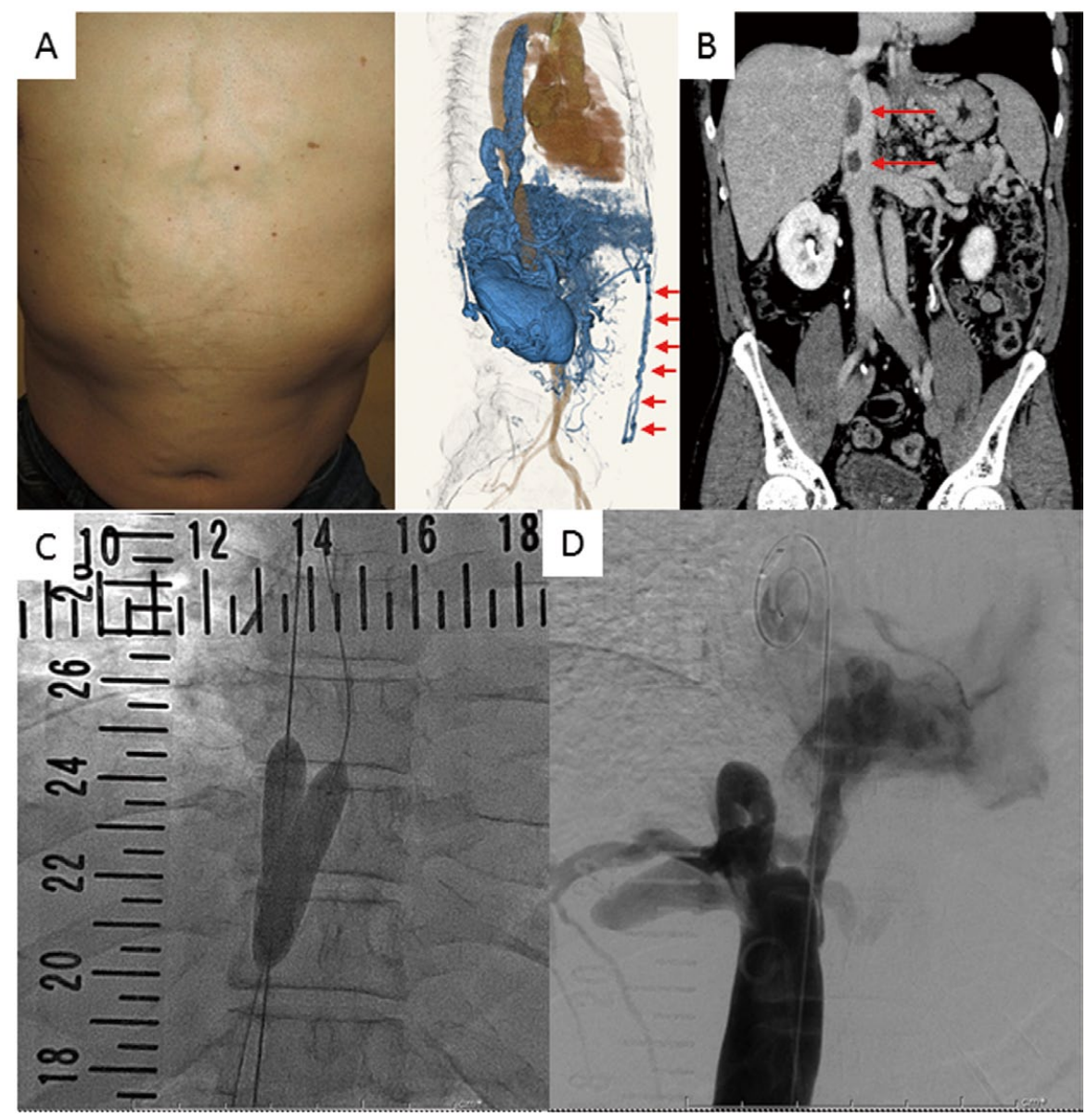

Figure. (A; Left) Dilated and distended veins in the anterior abdominal wall (caput medusa) in a patient with Budd-Chiari syndrome. (Right) Contrast-enhanced computed tomography (CT) of the abdomen, lateral view, showing well-developed venous collateral circulation in the abdominal wall (red arrows). (B) Enhanced CT showing a membrane-like obstruction of the inferior vena cava (IVC) at the suprahepatic level, and a large, free-floating thrombus in the IVC (red arrows). (C) Removal of a membranous, obstructive IVC lesion on percutaneous transluminal balloon angioplasty with the hugging balloon technique (10-mm semicompliant balloon; Armada, Abbott Vascular, USA). (D) Angiography showing the unobstructed IVC with good blood flow.

Received March 27, 2017; revised manuscript received May 2, 2017; accepted May 14, 2017; released online June 8, 2017 Time for primary review: 23 days

Division of Cardiology, Saiseikai Kumamoto Hospital Cardiovascular Center, Kumamoto, Japan

Mailing address: Eiji Taguchi, MD, Division of Cardiology, Saiseikai Kumamoto Hospital Cardiovascular Center, 5-3-1 Chikami, Minami-ku, Kumamoto 861-4193, Japan. E-mail: eiji-taguchi@saiseikaikumamoto.jp

ISSN-1346-9843 All rights are reserved to the Japanese Circulation Society. For permissions, please e-mail: cj@j-circ.or.jp 
A 49-year-old man presented with abdominal distension and shortness of breath. On admission, pulse rate was 55 beats $/ \mathrm{min}$, blood pressure was $126 / 90 \mathrm{mmHg}$ and body temperature was $36.7^{\circ} \mathrm{C}$. He was conscious and alert. The bulbar conjunctiva were nonicteric, and the palpebral conjunctiva were not pale. No respiratory rales or heart murmurs were noted on auscultation; but mild, bilateral, pitting pedal edema was observed. The abdomen was distended with dilated collateral veins over the anterior abdominal wall (caput medusae; Figure A). Palpation of the abdomen indicated splenomegaly.

Laboratory tests indicated mild thrombocytopenia $\left(12.4 \times 10^{4} / \mu \mathrm{L}\right.$; normal, $\left.>15 \times 10^{4} / \mu \mathrm{L}\right)$, elevated total bilirubin $(1.8 \mathrm{mg} / \mathrm{dL}$; normal, $<1.2 \mathrm{mg} / \mathrm{dL})$, elevated $\mathrm{NH}_{3}(84 \mu \mathrm{g} / \mathrm{dL}$; normal, $<70 \mu \mathrm{g} / \mathrm{dL}$ ), mildly elevated hepatic enzymes (serum glutamic oxaloacetic transaminase, $37 \mathrm{U} / \mathrm{L}$; glutamic pyruvic transaminase, $27 \mathrm{U} / \mathrm{L})$, mildly elevated biliary enzyme (serum alkaline phosphatase, 508 IU/L; normal, 106-322 IU/L), markedly elevated $\gamma$-glutamyl transpeptidase (368 IU/L; normal, 13-64 IU/L) and prolonged prothrombin time with an international normalized ratio of 1.57 . Ultrasonography and enhanced computed tomography (CT) showed a membrane-like complete obstruction of the inferior vena cava (IVC) at the suprahepatic level, and a large, free-floating thrombus in the IVC (Figure B). The patient had a history of treatment-refractory esophageal varices due to cirrhosis of the liver.

We diagnosed this patient as having Budd-Chiari syndrome (BCS) with a large free-floating thrombus in the IVC. The severity was grade III based on the Japanese guidelines.

The patient received direct oral anticoagulant (DOAC) therapy for 3 months (ELIQUIS ${ }^{\circledR}$ (apixaban), at a dose of $5 \mathrm{mg}$ twice daily). Follow-up imaging showed complete resolution of the IVC thrombus. Percutaneous transluminal balloon angioplasty (PTBA) was performed 3 months after initiation of DOAC (Figure C). The guidewire was inserted into the right atrium through the radiofrequency needle (Japan Lifeline) under intracardiac echocardiographic guidance, followed by successful double balloon dilatation without flow-limiting or embolic complications (Figure D). DOAC were continued for an additional 3 months.

To our knowledge, this is the first study to show that DOAC can produce favorable results in BCS. Three months of DOAC therapy, both before and after endovas- cular therapy, effectively resolved a large IVC thrombus in a patient with BCS.1,2 BCS is an uncommon condition caused by thrombotic or non-thrombotic obstruction of the hepatic venous outflow tract. Clinical features of the syndrome include hepatomegaly, ascites, and abdominal pain. Treatment of BCS is most successful when the disorder is diagnosed early. ${ }^{3}$ Treatment can include surgical intervention (shunting) or angioplasty with balloon dilatation alone or with stent placement. In severe cases, liver transplantation may be necessary. This strategy has a 5-year survival rate approaching $90 \%{ }^{4}$ Although there have been no reports of bleeding-related deaths in BCS on anticoagulation, few studies have investigated this issue. A recent study reported a high rate of anticoagulation-related complications in patients undergoing transhepatic interventional therapy. A surprisingly high rate of heparin-induced thrombocytopenia was observed, primarily with unfractionated heparin. Little is known about the optimal level of anticoagulation in BCS, ${ }^{5}$ and no previous studies have investigated the usefulness of DOAC before endovascular therapy in this patient population. In the present case, the IVC thrombosis completely resolved with the use of DOAC alone, leading to a successful vascular intervention without embolic complications in a patient with BCS.

\section{Conflict of Interest}

No conflict of interest.

\section{References}

1. Li T, Zhang WW, Bai W, Zhai S, Pang Z. Warfarin anticoagulation before angioplasty relieves thrombus burden in Budd-Chiari syndrome caused by inferior vena cava anatomic obstruction. $J$ Vasc Surg 2010; 52: 1242-1245.

2. He XH, Li WT, Peng WJ, Li YD, Tan HQ. Anticoagulation with warfarin for Budd-Chiari Syndrome with chronic inferior vena cava thrombosis: An initial clinical experience. Ann Vasc Surg 2011; 25: 359-365.

3. Plessier A, Sibert A, Consigny Y, Hakime A, Zappa M, Denninger $\mathrm{MH}$, et al. Aiming at minimal invasiveness as a therapeutic strategy for Budd-Chiari syndrome. Hepatology 2006; 44: $1308-1316$.

4. Valla DC. Primary Budd-Chiari syndrome. J Hepatol 2009; 50: 195-203.

5. Sharma S, Texeira A, Texeira P, Elias E, Wilde J, Olliff SP. Pharmacological thrombolysis in Budd Chiari syndrome: A single centre experience and review of the literature. $J$ Hepatol 2004; 40:172-180. 